“C 2014 IEEE. Personal use of this material is permitted. Permission from IEEE must be obtained for all other uses, in any current or future media, including reprinting/republishing this material for advertising or promotional purposes, creating new collective works, for resale or redistribution to servers or lists, or reuse of any copyrighted component of this work in other works." 


\title{
Compact Hyper-band Printed Slot Antenna: Design and Experiments
}

\author{
Ming-Chun Tang ${ }^{1}$ and Richard W. Ziolkowski ${ }^{2}$ \\ ${ }^{1}$ College of Communication Engineering, Chongqing University, Chongqing, China, tangmingchunuestc@126.com \\ ${ }^{2}$ Department of Electrical and Computer Engineering, University of Arizona, Tucson, AZ, USA, ziolkowski@ece.arizona.edu
}

\begin{abstract}
A compact hyper-band printed antenna design is designed numerically and measurements of a fabricated prototype confirm the predicted 10:1 input impedance bandwidth and radiation characteristics. It is based on an elliptical-slot antenna augmented with a parasitic oval patch and driven with a specially engineered microstrip-line-fed elliptical tuning fork element. The total size of the final optimized antenna is $30 \times 40 \mathrm{~mm}^{2}$; it exhibits a -10-dB impedance bandwidth from 2.26 to $22.18 \mathrm{GHz}$. While the hyper-band performance could be used for high fidelity pulse applications, the antenna also covers the entire ultra-wideband (UWB) spectral range from 3.1-10.6 GHz.
\end{abstract}

Index Terms-UWB antenna, impedance bandwidth, radiation efficiency, radiation pattern, measurements.

\section{INTRODUCTION}

Printed slot antennas have been investigated for their use in numerous wireless communication systems. They have many attractive practical characteristics including, for instance, low profile, light weight, cheap manufacturing, planar geometry, and ease of integration with other microwave devices $[1,2]$. In recent years various wide-slot antennas having different slot shapes have been reported which possess favorable wideband impedance bandwidth characteristics. These include, for example, rectangle [3], ellipse [4], circle [5, 6], and fractal [79] designs. Concomitantly, the directly driven elements in most of these antennas have specially engineered terminations of their feed lines to achieve suitable mutual coupling with the slots for optimum impedance matching levels over as wide a frequency range as possible. These terminations include, for example, square-patch- [10], triangle- [11], and circle- [12] shaped stubs.

Theoretically, all of these printed, wide-slot designs originate from the basic rectangle-shaped slot antenna [1] and possess an inherent abundance of resonance modes [2]. However, before effective tuning, their resonance frequency bands are not overlapping nor input impedance matched, for example, to a $50 \Omega$ source. This undesirable behavior is illustrated in Fig. 1(a). Usually, by tuning the stub and slot dimensions, the overlap and impedance matching characteristics of these resonances can be adjusted effectively to realize the desired large instantaneous impedance bandwidth.
In this paper, which is a brief summary of the more detailed report [13], a parasitic oval patch is embedded in the slot, which has an inherent abundance of resonance modes, to create additional resonance modes and to facilitate the overlap of various combinations of both sets of modes. Moreover, to provide additional tuning capabilities, the micro-strip line that feeds the slot is terminated in an elliptical-shaped tuning fork stub engineered to merge the resonance modes and to adjust their input impedance values to achieve nearly complete matching to a $50 \Omega$ source over a hyper-band $\left(2 *\left(f_{h}-f_{\nu}\right) /\left(f_{h}+f_{\nu}\right)>\right.$ $163.4 \%$ half-power fractional bandwidth with a $>10: 1$ bandwidth ratio, $f_{h} / f_{l}$, defined by the upper, $f_{h}$, and lower, $f_{l}$, half-power frequency points, a terminology borrowed from high power microwave (HPM) applications), while maintaining a compact size. The goal of the resulting design for its $\left|\mathrm{S}_{11}\right|$ values is illustrated in Fig. 1(b).

(a)

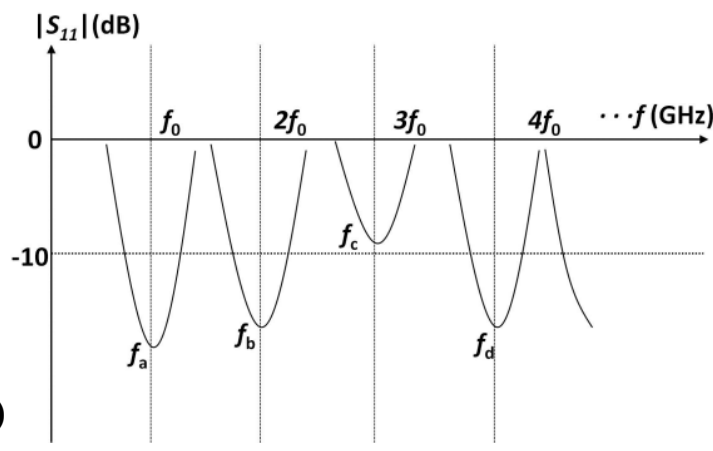

(b)

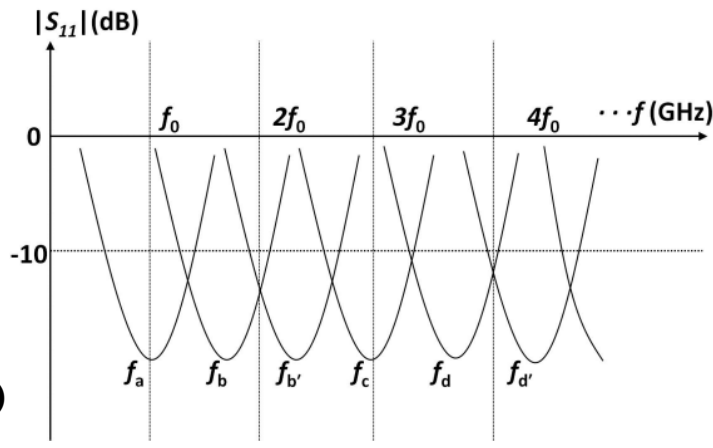


Fig. 1 Schematic of the impedance characteristics $\left(\left|S_{11}\right|\right)$ as a function of frequency. (a) Common printed wide-slot antenna before tuning; (b) proposed printed wide-slot antenna after refined tuning.

\section{DESIGN}

The geometry of the proposed antenna is illustrated in Fig. 2. This design is intended to be constructed using printed circuit board (PCB) technology. It presumes an FR4 substrate with the dielectric constant $\varepsilon_{r}=4.4$ and loss tangent $\tan \delta=0.02$. Its overall size is only $\mathrm{L} \times \mathrm{W} \times \mathrm{H}=40 \mathrm{~mm} \times 30 \mathrm{~mm} \times 1.6 \mathrm{~mm}$. An elliptical shaped slot is centered on the top side of an FR4 board. An oval shaped (two conjoined half ellipses) parasitic patch located in the slot with its center displaced from the slot center by $\mathrm{p}=2.4 \mathrm{~mm}$. On the bottom side, a microstrip feed line designed to have a $50 \Omega$ characteristic impedance (width $\mathrm{W} 2=3.35 \mathrm{~mm}$ ) is terminated in a fork-shaped tuning stub. The design refinements were obtained numerically with both the ANSYS/ANSOFT high frequency structure simulator (HFSS) and CST's Microwave Studio (MWS).

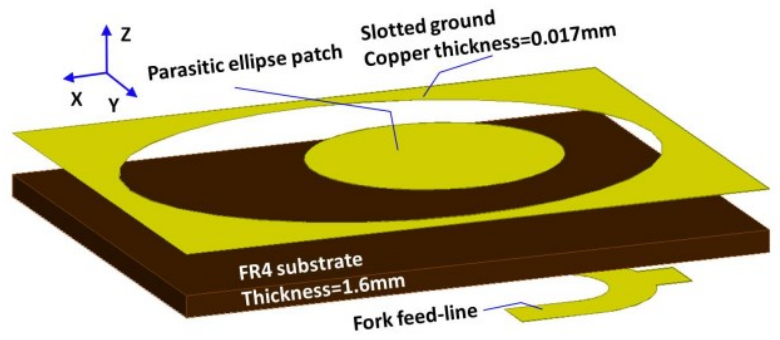

(a)

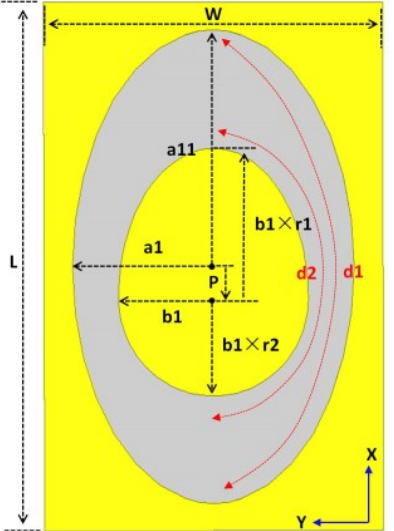

(b)

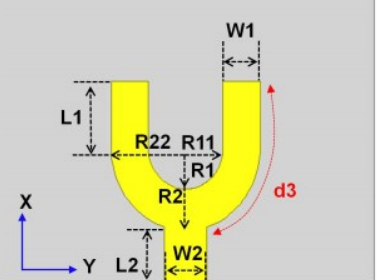

(c)
Fig. 2. Configuration of the printed hyper-band antenna (a) 3-D, (b) top and (c) back views. Design parameters (all dimensions in $\mathrm{mm}$ ): $\mathrm{L}=40, \mathrm{~W}=30$, $\mathrm{L} 1=5, \mathrm{~L} 2=2.347, \mathrm{~W} 1=2.9545, \mathrm{~W} 2=3.35, \mathrm{R} 1=3.14, \mathrm{R} 2=6.25, \mathrm{R} 11=2.983$, $\mathrm{R} 22=5.9375, \quad \mathrm{p}=2.4, \quad \mathrm{a} 1=12.4584, \quad \mathrm{a} 11=17.9, \quad \mathrm{~b} 1=8.4, \quad \mathrm{r} 1=1.35, \quad \mathrm{r} 2=0.88$, $\mathrm{d} 1=48.071, \mathrm{~d} 2=28.005$ and $\mathrm{d} 3=12.873[13]$

\section{VALIDATION}

The antenna shown in Fig. 2 was fabricated and its performance characteristics were obtained experimentally. The prototype is shown in Fig. 3. First, the reflection coefficient of the antenna was measured using Agilent E8361A PNA Vector Network Analyzer (VNA) with the measurement scale
$0.01 \mathrm{GHz}-67 \mathrm{GHz}$. The measured results together with the corresponding simulation values are plotted in Fig. 4. As anticipated from the HFSS (CST) simulation results, the antenna provided a $>10: 1$ impedance matching bandwidth with $\left|\mathrm{S}_{11}\right|<-10 \mathrm{~dB}$ from 2.17 (2.16) to $23.01 \mathrm{GHz}(22.72 \mathrm{GHz})$. The experimental results demonstrate that the antenna has a -10dB-level impedance bandwidth from 2.26 to $22.18 \mathrm{GHz}$ (163.01\% fractional bandwidth, $\sim 10: 1$ bandwidth ratio).

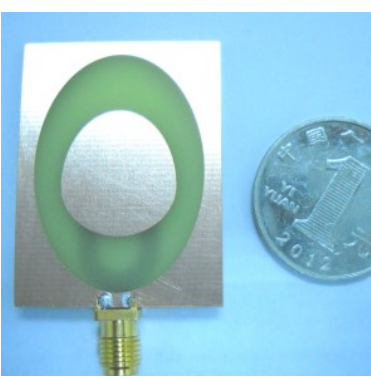

(a)

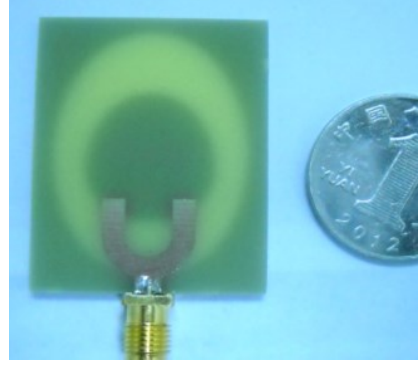

(b)
Fig. 3. Fabricated prototype of the antenna. (a) Front view, and (b) back view [13].

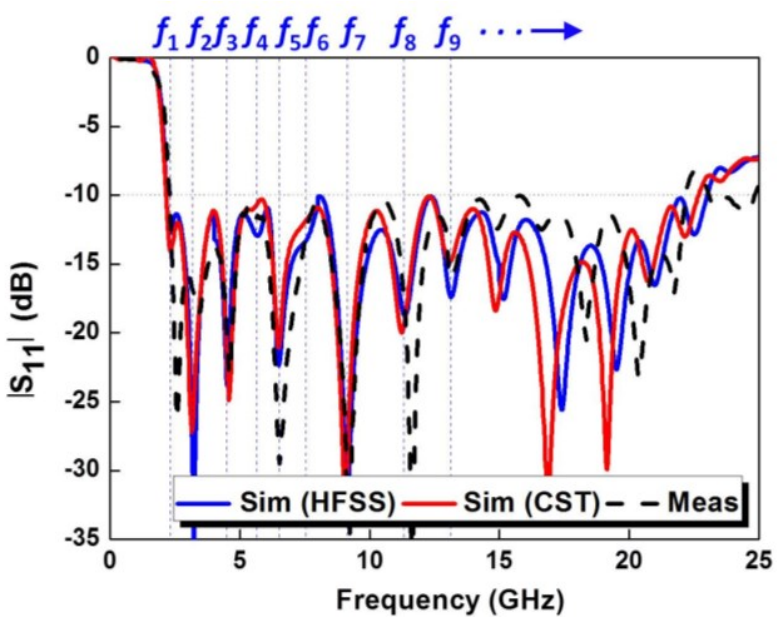

Fig. 4. Measured and simulated input impedance characteristics $\left(\left|\mathrm{S}_{11}\right|\right.$ in $\left.\mathrm{dB}\right)$ of the slot antenna shown in Figs. 2 and 3 [13].

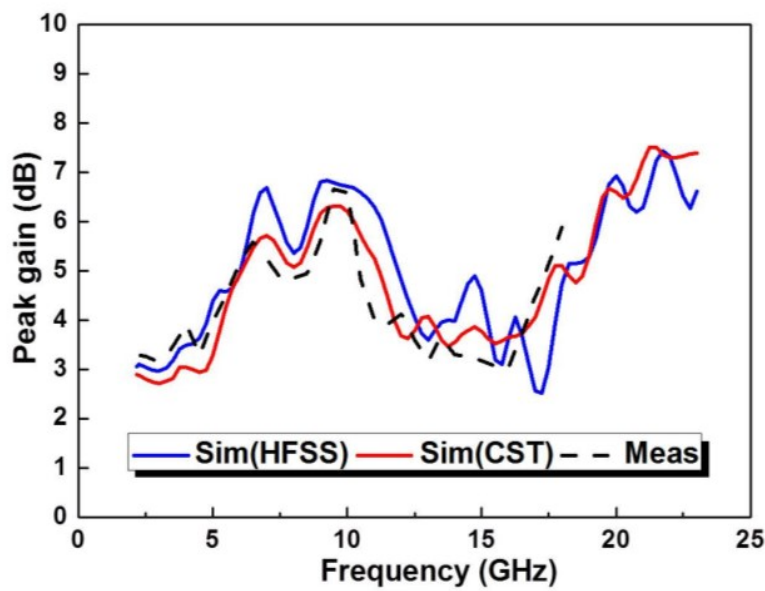

Fig. 5 Measured and simulated peak gain values [13]. 
The measured maximum gain values together with their simulated values are presented in Fig. 5. It is observed that the measured maximum gain fluctuates within the range from $3.14 \mathrm{~dB}$ to $6.59 \mathrm{~dB}$ in the range from 2.26 to $12.0 \mathrm{GHz}$. Since this frequency range covers the $2.4 / 5.2 / 5.8 \mathrm{GHz}$ WLAN bands, 2.5/3.5/5.5 GHz WiMAX bands, and 3.1-10.6 GHz UWB band, the proposed antenna would be a good candidate in any of the above wireless communication applications. Also, the HFSS and CST simulated radiation efficiencies over the entire operation frequency range, as shown in Fig. 6, are higher than $75 \%$. The measured $\left|S_{11}\right|$ and maximum gain values confirm this behavior.

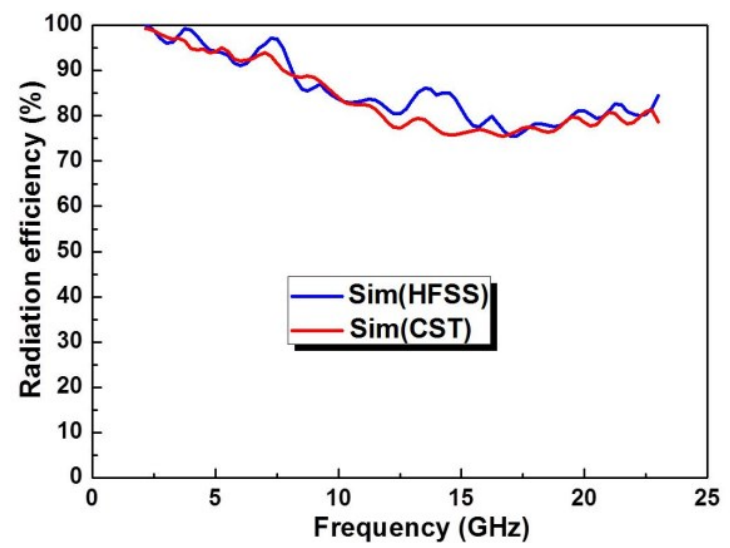

Fig. 6 HFSS and CST simulated radiation efficiency values.

On the whole, the measurement and simulations agree very well with each other and provide the desired hyper-band performance (note that the half-power bandwidth values are even larger than the reported $-10 \mathrm{~dB}$ bandwidths). Note that the measured frequencies are shifted about $0.1 \mathrm{GHz}$ higher than the simulation results due to the presence of a long coaxial cable used in the measurements. We believe the slight decrease in the measured bandwidth at the upper bound is due to minor fabrication issues.

Comparisons of the predicted and measured radiation patterns will be given in our presentation. A more detailed discussion of the design parameters and their impacts on the radiation characteristics of this antenna will also be given.

\section{CONCLUSION}

A compact-sized elliptical-slot antenna augmented with a parasitic oval patch and fed with a microstrip line terminated in an elliptically-shaped tuning fork stub has been studied numerically and experimentally. The measured results demonstrated that by optimizing the parasitic oval patch in the slot and the tuning fork stub, the antenna could exhibit a hyperband -10dB-impedance bandwidth from 2.26 to $22.18 \mathrm{GHz}$ and have reasonably stable radiation patterns, high radiation efficiencies and high gain values in a broad bandwidth. The measured performance characteristics are quite suitable for the WLAN, WiMAX, and UWB frequency domain applications, as well as for high fidelity, short pulse, and time domain applications.

\section{REFERENCES}

[1] M. Kahrizi, T. K. Sarkar, and Z. A. Maricevic, "Analysis of a wide radiating slot in the ground plane of a microstrip line," IEEE Trans. Microwave Theory Tech., vol. 41, no. 1, pp. 29-37, Jan. 1993.

[2] K. L. Wong, Compact and Broadband Microstrip Antennas. New York: Wiley, 2002.

[3] W. S. Chen, "A novel broadband design of a printed rectangular slot antenna for wireless communications," Microw. J., vol. 49, no. 1, pp. 122-130, Jul. 2006.

[4] P. Li, J. Liang, and X. Chen, "Study of printed elliptical/circular slot antennas for ultrawideband applications," IEEE Trans. Antennas Propag., vol. 54, no. 6, pp. 1670-1675, Jun. 2006.

[5] S. -W. Qu, J. -L Li, J. -X. Chen, and Q. Xue, "Ultrawideband striploaded circular slot antenna with improved radiation patterns," IEEE Trans. Antennas Propag.,vol.55,no.11,pp. 3348-3353, Nov. 2007.

[6] T. A. Denidni and M.A. Habib, "Broadband printed CPW-fed circular slot antenna," Electron. Lett., vol. 42, no. 3, pp. 135 - 136 Feb. 2006.

[7] W. -L. Chen, G. -M. Wang, and C.-X. Zhang, "Bandwidth enhancement of a microstrip-line-fed printed wide-slot antenna with a fractal-shaped slot," IEEE Trans. Antennas Propag., vol. 57, no. 7, pp. 2176-2179, Jul. 2009.

[8] D. D. Krishna, M. Gopikrishna, C. K. Anandan, P. Mohanan, and K. Vasudevan, "CPW-fed Koch fractal slot antenna for WLAN/WiMAX applications," IEEE Antennas Wireless Propag. Lett., vol. 7, pp. 389392, 2008.

[9] D. D. Krishna M. Gopikrishna C.K. Aanandan P. Mohanan, and K. Vasudevan, "Compact wideband Koch fractal printed slot antenna," IET Microw. Antennas Propag., Vol. 3, Iss. 5, pp. 782-789, 2009.

[10] S.-W. Qu, C. Ruan, and B.-Z. Wang, "Bandwidth enhancement of wideslot antenna fed by CPW and microstrip line," IEEE Antennas Wireless Propag. Lett., vol. 5, pp. 15-17, 2006.

[11] Y. Liu, K. L. Lau, Q. Xue, and C. H. Chan, "Experimental studies of printed wide-slot antenna for wide-band applications," IEEE Antennas Wireless Propag. Lett., vol. 3, pp. 273-275, Dec. 2004.

[12] T. A. Denidni and M.A. Habib, "Broadband printed CPW-fed circular slot antenna," Electron. Lett., vol. 42, no. 3, pp. 135 - 136 Feb. 2006.

[13] M.-C. Tang, R. W. Ziolkowski, and S. Xiao, "Compact hyper-band printed slot antenna with stable radiation properties," submitted to IEEE Trans. Antennas Propag., July 2013. 